University of Nebraska - Lincoln

DigitalCommons@University of Nebraska - Lincoln

Publications from USDA-ARS / UNL Faculty

U.S. Department of Agriculture: Agricultural

Research Service, Lincoln, Nebraska

2016

\title{
The worm's eye view of community ecology
}

Tavis K. Anderson

USDA-ARS, tavis.anderson@ars.usda.gov

Michael V. K. Sukhdeo

Rutgers University

Follow this and additional works at: https://digitalcommons.unl.edu/usdaarsfacpub

Anderson, Tavis K. and Sukhdeo, Michael V. K., "The worm's eye view of community ecology" (2016).

Publications from USDA-ARS / UNL Faculty. 1620.

https://digitalcommons.unl.edu/usdaarsfacpub/1620

This Article is brought to you for free and open access by the U.S. Department of Agriculture: Agricultural Research Service, Lincoln, Nebraska at DigitalCommons@University of Nebraska - Lincoln. It has been accepted for inclusion in Publications from USDA-ARS / UNL Faculty by an authorized administrator of DigitalCommons@University of Nebraska - Lincoln. 


\title{
The worm's eye view of community ecology
}

\author{
Tavis K. Anderson ${ }^{a}$ and Michael V. K. Sukhdeo ${ }^{b}$ \\ ${ }^{a}$ Virus and Prion Research Unit, National Animal Disease Center, USDA-ARS, Ames, Iowa U.S.A. \\ ${ }^{b}$ Department of Ecology, Evolution, and Natural Resources, and Center for Research on Animal Parasites, Rutgers University, \\ New Brunswick, New Jersey, U.S.A.
}

The study of parasites in the context of community level organization, either as parasites embedded within host communities, or as parasite communities themselves, is now quite prevalent in parasitology and ecology today. However, this was not always the case. In terms of publications, there was almost no consideration of parasite interactions at the community level for most of the first half of the last century. Papers in The Journal of Parasitology by Clark Read (1951) and John Holmes (1961) were the defining contributions to the beginning of the field, and the ideas elaborated by these two parasitologists still inspire current debates on parasite community structure today. There are several probable explanations for why investigation of parasite communities was not popular during the early part of the century. Most likely, it was related to funding sources, and the strong biomedical rubric that has guided parasitological studies for most of the last century. The intensity of focus on treatment and control of parasites of medical and veterinary importance often resulted in indifference to the natural and evolutionary histories of the parasites. Fortunately, this situation has changed, and there has been an exponential growth of ideas based on ecological and evolutionary theory, especially since the beginning of this century. We are now entering into areas of inquiry that the early investigators probably never dreamed of. For example, it was only in 1997 that "Food webs: A plea for parasites" by Marcogliese and Cone (1997) made eloquent arguments for why parasites should be included in studies of food webs and ecosystems. This paper was an explicit call to action for community-minded parasitologists, and it ignited a huge transformation in the way ecologists and evolutionary biologists began to look at parasites in nature. Studies on the roles of parasites in food webs, an area that was almost totally ignored by ecologists for eight decades, are now fairly common (Sukhdeo, 2012).

The first significant article in The Journal of Parasitology to report the existence of interactions between parasite species was a Research Note by Cross (1934). He studied natural co-infections of two phylogenetically distant species, an acanthocephalan and a tapeworm, sharing the same fish host. The tendency of large numbers of one species of parasites to limit infection by other parasite species was reported by other parasitologists (Ward, 1912; Wilson, 1916), but Cross was the first to unambiguously demonstrate the existence of negative interactions between two parasite species under natural conditions. He necropsied 92 cisco fish from Silver Lake in Wisconsin that were infected with only two parasite species, a cestode Proteocephalus exigus and an acanthocephalan identified to genus Neoacanthorinchus. His interesting observation was that although co-infections occurred, fish with more than 15 individual acanthocephalans rarely had any tapeworms, whereas fish with more than 25 tapeworms rarely had any acanthocephalans (fish with fewer parasites of each species had co-infections with similar intensities of each parasite). Cross' graph of the relationship between the two parasite species (Fig. 1) is one of the most elegant

A Century of Parasitology: Discoveries, ideas and lessons learned by scientists who published in The Journal of Parasitology, 1914-2014, First Edition. Edited by John Janovy, Jr and Gerald W. Esch.

() 2016 John Wiley \& Sons, Ltd. Published 2016 by John Wiley \& Sons, Ltd. 


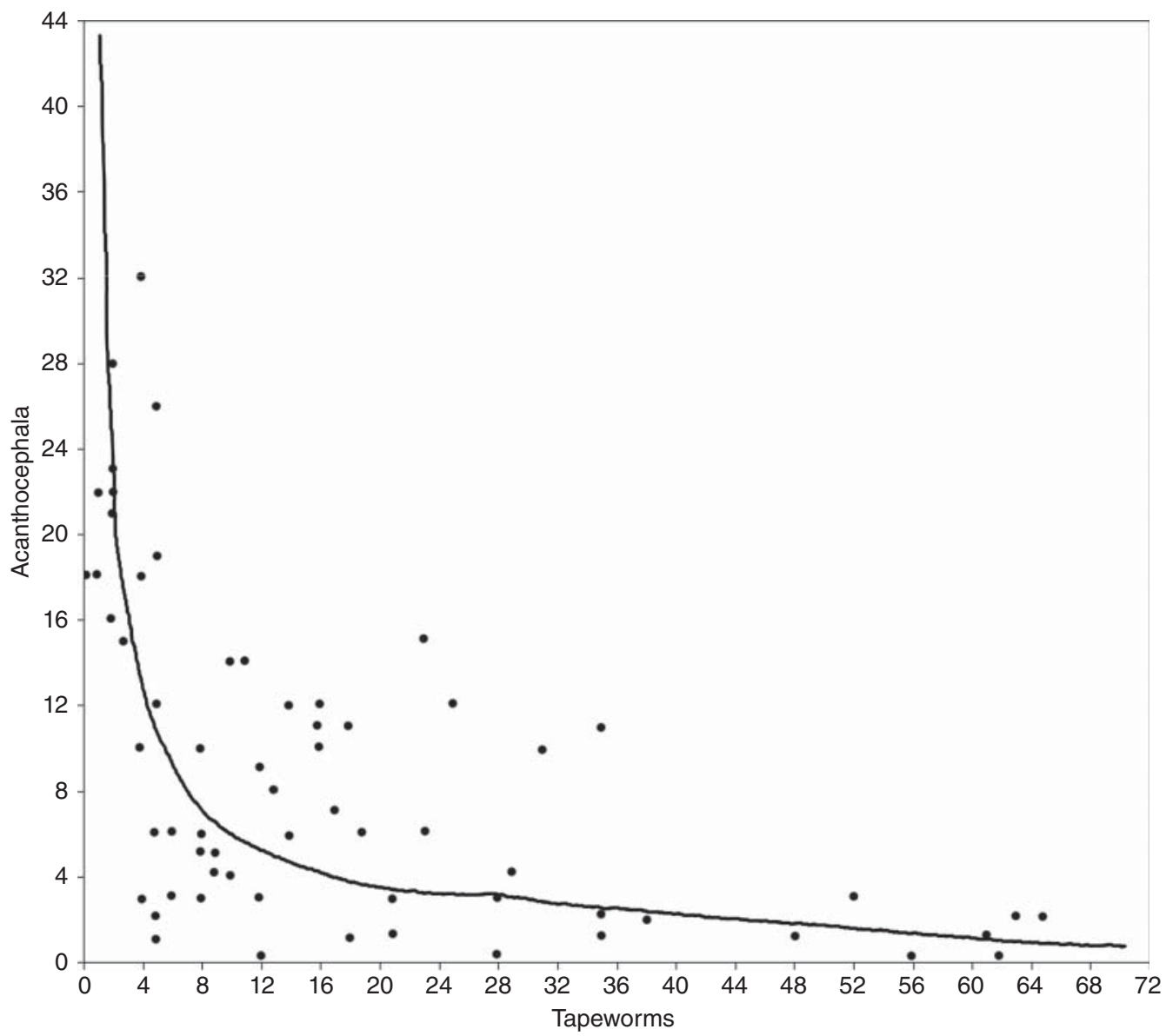

Figure 1 Degree of infection of an individual fish. Redrawn from Fig. 1 of Cross (1934) Journal of Parasitology 20: $244-245$. Reproduced with permission of Allen Press Publishing Services.

demonstrations of negative parasite interactions that we have seen, and it is a major reason why we think this paper is the appropriate seed paper for a chapter on parasite community ecology.

Cross showed that there was a clear mutually inhibitory effect of each parasite on the other, but the proximate mechanisms of the negative interactions were unclear. He ruled out interspecific competition as the cause for these negative interactions because each species occupied different parts of the small intestine. At this time, mainstream ecologists were still struggling with defining interspecific competition in a meaningful way. The mathematical extension of Pearl and Read's 1920 logistic equation to describe the influence of one species on another had only been recently developed
(Lotka, 1925; Volterra, 1926). These descriptive models appeared to fit the types of dynamics observed in experimental studies with free living species, including the famous study by Gause (1932) showing that yeast grown in a mixed population achieved lower densities than when grown in monoculture. However, it is unlikely that these ideas had yet trickled down to parasitology. An earlier article in the journal reported that snails infected with Schistosoma sp. were resistant to infection with the metacercariae of the Cotylurus flabelliformis, because of a non-specific immune response (Nolf and Cort, 1933), and Cross tentatively invoked a similar idea of indirect non-specific immune responses to explain his observations. Nevertheless, his questions on whether the negative interspecific effect was the result 
of direct competition, or if it was indirectly mediated through the host immune response, would presage much of the future work on parasite co-infections. This was somewhat unfortunate for the biological study of direct interactions between parasite species, because over the next several decades, the field would be taken over by the hundreds of studies on the indirect immunological regulation of concurrent infections between all possible combinations of protozoan and helminth parasites (Cox, 2001).

An earlier iteration of this chapter used a seed paper that exhaustively detailed a 3-year study of cattle infected with several co-occurring nematode species that persisted in a single pasture (Field 27) into which no other cattle were allowed after the first colonizing group (Stoll, 1936). The study explored whether the cattle parasites could persist without re-infection, whether cattle parasites could infect sheep, and if fecal flotation was a valid diagnostic tool. Stoll's conclusions that cattle parasites could persist "naturally" without re-infections and that sheep could be infected with cattle parasites may sound trivial today, but it had significant meaning for farmers and agriculturalists in the 1930s. In addition, fecal flotation is now a standard diagnostic tool. Nevertheless, that was as far as his interest in interspecific parasite interactions went and although he tracked multiple infections in his animals, he did only the barest of analyses. It was a sign of the times because ecological frameworks for interspecific competition were only just being developed, although not for parasites. If available today, the enormous amount of information he collected on the seasonality, prevalence and intensity of infections among the parasite communities, could be the basis for several theses.

\section{Crowding and competition}

The Cross paper laid the foundations for the classic 1961 paper on tapeworm/acanthocephalan interactions by John Holmes. This Holmes paper is a classic in the real sense of the word, because it is still cited by almost every author now working on interspecific parasite interactions. However, before we get to Holmes, we must first discuss a paper published in 1951 by C. P. Read on the "crowding effect" in $H$. diminuta. This was a transformative paper published in our journal, and one of the first studies to create a meaningful linkage between the fields of parasitology and ecology. Read reported that in crowded infections, individual tapeworms were smaller than individuals from uncrowded infections, and it was this demonstration of competition in parasites that opened the door for ecological ideas in parasitology. Competition and predation are the two major forces thought to regulate free living populations, and these forces are still the subjects of intense scrutiny by ecologists today. Although it is easy to invoke competition in biological systems, competition is extremely difficult to demonstrate.

The crowding effect in tapeworms was an interesting model because, unlike most free-living systems, it is not confounded by the effects of predation. The idea that parasites could compete for resources was already established prior to Read's work, and several investigators had reported that in cestode infections, the size of the worms was inversely proportional to the number of worms in a given infection. This was seen with Hymenolepis nana infections of rats and mice (Woodland, 1924; Shorb, 1933; Hunninen, 1935) and also with infections by $H$. diminuta in rats (Chandler, 1939; Hager, 1941). However, these ideas really only coalesced with Read's carefully controlled studies of worm length and weight in tapeworms of the same age (38-44 days post infection) infecting male rats of similar size (190-208 g). This paper provided indisputable evidence that multiple infections of a single species produced worms were individually smaller than the tapeworms from single infections. In the absence of predators, density-dependent competition for scarce resources could be the only explanation, and in subsequent papers, Read was able to demonstrate that the resources being competed for were carbohydrates that occurred in limited concentrations in the gut (Read, 1959). The enormous advantage was that this study provided a laboratory model that was easy to work with and totally reliable. In fact, the demonstration of the crowding effect in tapeworms is so reliable it is often used as a standard laboratory exercise in many undergraduate parasitology courses.

There was a huge bolus of papers following Read's paper (many in The Journal of Parasitology) that demonstrated the crowding phenomenon in almost all classes of helminths, although the best results came from tapeworm studies. Competition for limited resources is called exploitative competition, and while this mechanism is not the exclusive one in intraspecific interactions, it is 
the most common proximate mechanism for crowding effects in parasites. In the case of $H$. diminuta, competition is for limited carbohydrate resources (Read, 1959; Read and Phifer, 1959), but in other parasites it may be for space for attachments sites or for mates (Bansemir and Sukhdeo, 2001; Sukhdeo and Sukhdeo, 2004). Although reductions in size or body weight are the most common response to crowding, this may not always be the case, and instead, as seen in crowded pinworms of insects, there may be significant reductions in per capita egg production (Zervos, 1988a; b). Intraspecific competition may also be mediated through chemical means, or interference competition, and there are several examples of parasites which secrete toxins to specifically target their conspecifics (Poulin, 2007). The situation is complicated further in many situations by the indirect effects of immune responses precipitated by the parasite's infection (Cox, 2001).

Crowding is by definition, competition, pure and simple. So, it is perhaps not surprising that as we have dug deeper into the subject, the ripple effect of crowding has proven to be quite wide-ranging. The effects may be positive: for example, crowding may benefit some host-manipulating metacercariae where the appropriate changes in host behavior are dependent on parasite-intensity (Weinersmith et al., 2014); or effects may be negative, as on conspecifics (Read, 1951). Defining and measuring crowding has been a problem, and the great variety of parasite models used in crowding studies have raised the call for an objective definition of crowding in parasites, especially since responses may be species-specific and density-dependent regulation may depend on threshold infrapopulation sizes of each species (Poulin, 2007). Indeed, there are now several indices and statistical tools to define crowding in parasites, but these have yet to be validated (Neuhäuser and Poulin, 2004; Reiczigel et al., 2005). Nevertheless, despite the imprecision of our current metrics, an exciting realization has been that crowding-induced inequalities in body size among adult helminths can result in inequalities in reproductive output via their impacts on growth and mating probabilities (Poulin, 2007). For example, for some larval helminths in intermediate hosts, crowded conditions early in life can have a significant negative effect on the fitness of adult parasites (Fredensborg and Poulin, 2005; Heins et al., 2010), thus having considerable consequences for the parasite's population dynamics. These long term biological effects of parasite crowding are in an area that is ripe for research, and it is a testament to Read's work that his paper is cited in almost all of these studies.

\section{Interspecific interactions among parasites}

From Read's paper, we fast forward 10 years to a paper by John Holmes who published his Ph.D. thesis on interspecific interactions as a series of papers starting in 1961. Interspecific interactions in parasites had been demonstrated in a series of experiments on concurrent infections between $H$. diminuta and the closely related Hymenolepis citelli, that demonstrated loss of weight for each species, and this result was clear evidence of interspecific effects (Read and Phifer, 1959). However, Holmes' (1961) demonstration of negative interspecific effects between two phylogenetically distant parasites, tapeworms and acanthocephalans, became the definitive work. Again, his advantage was a laboratory model that allowed careful experimental control of co-infections, and quantitative measures of each worm's position provided indisputable evidence that in the presence of the acanthocephalan parasite, the tapeworm relocated in the intestine (Holmes, 1961, 1962a, 1962b); and his graphical representation of this response is elegant (Fig. 2).

Following Holmes, much of parasite community ecology has continued to explore infracommunity processes, i.e. all parasite infrapopulations in a single host (Bush et al., 1997), because experimental manipulations of entire infrapopulations are possible, and because it is the only level at which different parasite populations meet and interact. Thus, the interactions between species within infracommunities can determine how parasite species can coexist within a single host, and one of Holmes' major contributions was a public and prolonged debate over whether infracommunities of parasites formed isolationist (non-interactive) versus interactive communities. These two possibilities formed the basis of a long-running, good-natured debate between Holmes and Peter Price (see Janovy, 2002), which stimulated much discussion, and provided a huge incentive for continued experimentation by young scientists. The debate is now mostly moot, because the cumulative evidence suggests that interactions among parasite species can range along a continuum from isolationist to interactive, and that much depends on 


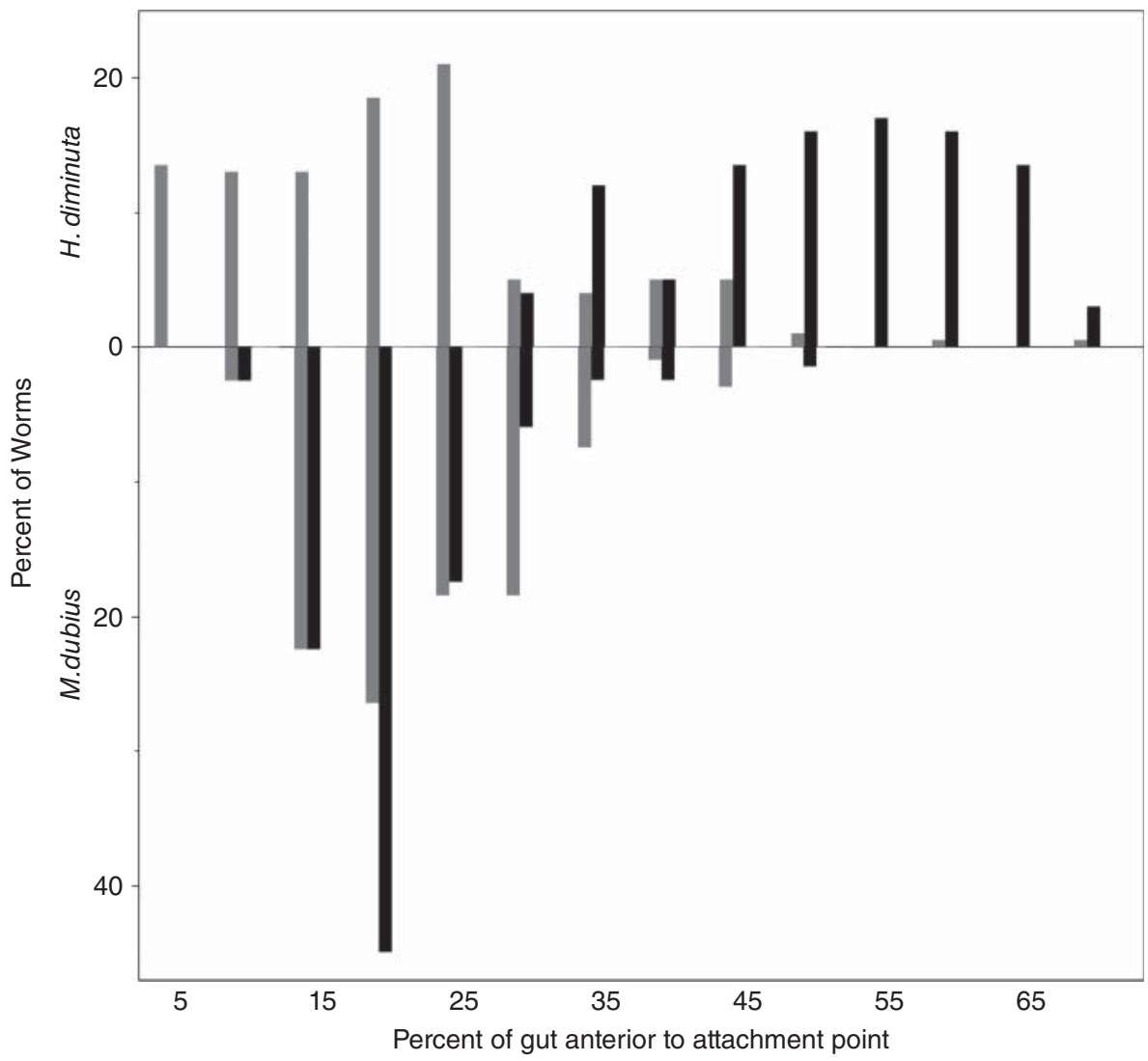

Figure 2 Effects of concurrent infection on the intraintestinal distribution of Hymenolepis diminuta and Monilformis dubius. Light bars are single infections; dark bars are concurrent infections. Redrawn from Figure 1 of Holmes (1961) Journal of Parasitology 47: 209-216. Reproduced with permission of Allen Press Publishing Services.

the evolutionary and ecological history of each species (Goater et al., 1987; Cabaret and Hoste, 1998; Dove, 1999; Poulin, 2007). However, at the time, the debate often became polarized. The interactions between parasite species were thought to be key to understanding of infracommunity structure in nature, but it was not at all clear that lab results translated appropriately into natural infections. Holmes himself had reported that the results from the rat studies could not be repeated in hamsters (Holmes, 1962a, 1962b), indicating a role for other factors in the responses.

In the years following Holmes' seminal paper, there were hundreds of publications on concurrent infections, mostly products of rigorous experimental protocols in the lab, and that more often than not, were primarily concerned with the immune responses involved. Thus, the process of dissecting the biological relevance of interspecific interactions was slow and tortuous, and over the decades, there have been many articles and scores of reviews on the subject. A general theory of parasite infracommunity structure has remained elusive, but the profusion of literature on the subject makes it challenging to deal comprehensively with the topic of interspecific parasite competition in this short chapter, so we will focus only on a few highlights of the debate. For more details, readers are referred to the following: Holmes and Price (1986); Price (1987); Esch et al. (1990a, 1990b); Sousa (1994); Poulin (1997); Janovy (2002); Poulin (2007).

The isolationist view was that, in nature, parasites most likely did not encounter each other frequently enough for interactions to evolve. Parasites that are spatially separated, e.g., ticks and tapeworms in the same host, were unlikely to interact. Even if they were close to each other in the host, parasite site specificity is usually very narrow, and interspecific interactions 
would be unlikely to occur even among parasites in the same organ (Price, 1980). The almost complete spatial separation of eight co-occurring related pinworm species crowded into the rectum of turtles (Schad, 1963) was often used to support this idea. In cases like these, it was thought that in order to maximize reproductive success, selection may have favored a narrowing of the niche. For instance, the reproductive success of helminths may vary as a function of each worm's position in the gut (Sukhdeo, 1991). This specialization could produce isolationist parasite communities if location of the niche of one species is independent of the presence of other species.

In fact hosts may have many vacant niches (Rohde, 1993a), obviating the need for competitive interactions. Furthermore, parasite infrapopulations are aggregated in their hosts (Crofton, 1971; Shaw and Dobson, 1995), and large parasite infrapopulations tend to occur in only a relatively few hosts. Theoretically, if the aggregated distributions of different parasite species are independent of one another, competition is unlikely to occur because there are likely to be very few opportunities for two or more species of parasites to encounter each other (Poulin, 2007). Indeed, there have been strong arguments against any significant roles for interspecific interactions in determining infracommunity structure in natural assemblages (Esch et al., 1990b; Fernandez and Esch, 1991a, 1991b). Comprehensive long-term studies by Esch and colleagues suggested that the mortality rates of most parasites in hosts under natural conditions were independent of infrapopulation density (Esch and Fernandez, 1994). Instead, parasite density and prevalence tended to be related to seasonal changes in temperature and other physical factors in the environment, or of natural senescence and mortality within the host population, and not the result of interspecific interactions. For example, in freshwater snails studied by Esch and Fernandez, a new cohort may replace the existing one every year, and as snails die, so do their parasite communities. Replacement of their infracommunities was an annual event that occurred independent of any interspecific competitive effects (Esch and Fernandez, 1994).

However, it was equally clear since the work of Cross (1934), that negative interspecific parasite interactions do occur in nature, but it was not evident whether it was as common and pervasive as Holmes suggested. Co-occurrences of pairs of species that are more or less frequent than expected by chance, can provide strong evidence that species interactions exist and act on community structure. However, deducing the presence of interspecific interactions between helminth species from patterns in community structure is a convoluted process (Esch et al., 1990). In laboratory experiments, changes in numbers of parasite individuals or in their function roles related to niche utilization or reproductive output are easily demonstrated by comparing with controls. Field studies can only provide indirect, circumstantial inferences based on patterns in the distribution of species richness or species composition in infracommunities from naturally infected hosts. Controls are usually the random patterns predicted by appropriate null models (Poulin, 2007), and in many cases, the alternative explanations for presumed patterns may be equally as plausible as the effect of interactions among helminth species.

When parasite species interact negatively, the outcome can take various forms, including spatial displacement across potential sites, or reduction in numbers and biomass of one or more participants. Most negative interactions are the result of exploitative or interference competition, but there can be other mechanisms, including predation. For example, in some host snails from natural populations, mixed species infections with larval trematode species are less frequent than expected by chance. While several mechanisms might generate such negative associations, laboratory studies demonstrated the effects of strong predatory interactions between larval stages of species that infect the same host snail (Sousa, 1992, 1993). More recent studies have demonstrated that some species of these interactive trematodes may have evolved a caste system, producing warrior castes (small forms with aggressive behavior and large oral suckers) that will specifically attack and destroy competitors (Hechinger et al., 201 lb).

However, not all interactions between parasite species are negative, and there are several situations where positive interactions might occur (Dobson and Pacala, 1992; Bucknell et al., 1996; Cabaret and Hoste, 1998; Sanmartín et al., 2000; Janovy, 2002; Luque et al., 2004). An exciting example is seen in the hitchhiking strategy, where a non-manipulating trematode preferentially infects intermediate hosts that are already infected with a manipulating parasite (Thomas et al., 1998). Parasite species sharing an intermediate host population with a manipulator species would benefit by 
associating with the manipulator, as they would obtain a cost-free ride to a shared definitive host (Thomas et al., 1998; Lafferty, 1999). In many cases like these, positive interactions have to be inferred from changes in species composition and abundance. Thus we must be cautious with these inferences because there are several factors that can generate spurious covariances and affect the sign of associations, e.g., a major source of bias is the number of hosts sampled (Lotz and Font, 1994; Dove, 1999).

Regardless of whether there are negative, positive, or no interactions between parasite species, at the heart of the matter is the potential evolutionary costs of such interactions. Interactive strategies would require the sensory apparatus to recognize competitors or cooperators, and behavioral or other mechanisms (toxins, weapons) to deal with the competitor or cooperator. These mechanisms would be very costly investments for only rare encounters with the enemy or friend. Interspecific interactions are a product of coexistence strategies, and these are determined by the forces that assemble parasite communities. Thus, if parasite species co-occur at the same site in the same host at the same time, and this situation occurs frequently over evolutionary periods, these parasites might evolve interactive strategies. For example, in systems where snails concurrently serve as hosts to several trematode species, antagonistic competition ensues (Sousa, 1993). However, in systems where different species only co-occur infrequently or where the parasite species are subject to extensive spatial and temporal heterogeneity, interspecific interactions are unimportant (Curtis and Hubbard, 1993; Curtis, 1997; Esch et al., 1997).

Much of this will be dealt in a later section of this chapter, and the reader is referred to our hierarchical model of parasite community assembly (Fig. 3). Our

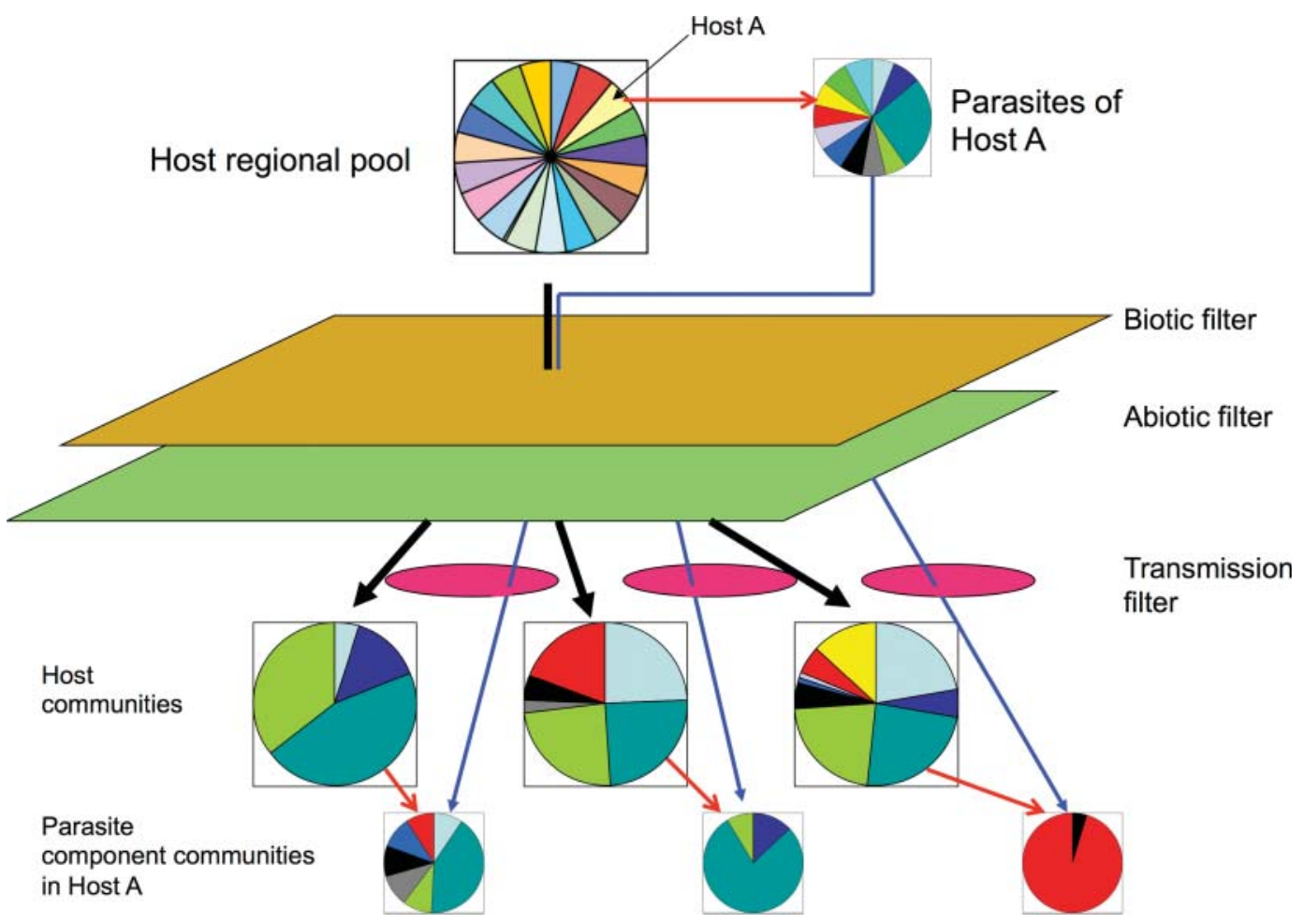

Figure 3 Parasite community assembly is influenced by processes operating at a range of spatial and temporal scales. Parasite species are found within a regional species pool that is constrained by evolutionary processes. A subset of the species from the regional pool will colonize a particular site depending on dispersal and exposure probability. This, in essence, suggests that the observed parasite community within a host is the result of infective stages passing through abiotic and biotic filters. Modified from HilleRisLambers, J., P. B. Adler, W. S. Harpole, J. M. Levine, and M. M. Mayfield. 2012. Rethinking community assembly through the lens of coexistence theory. Ann. Rev. Ecol. Evol. Syst., 43: 227-248. 
model argues that several biotic and abiotic factors acting on the host and on the success of parasite transmission stages, determine infracommunity structure in nature. The list of potential forces that can have significant impacts on community structuring processes is quite long, and at a minimum these factors include host longevity, host size, host diet, pool of available parasites, shared intermediate hosts, temporal and spatial heterogeneities, various abiotic conditions, generalist versus specialist natures of parasites, and host phylogenies. These influences are further complicated by various stochastic events related to local occurrences such as the probability of infection, host populations size, and colonization strategies by regional parasite pools (Esch et al., 1988; Kennedy, 1990; Valtonen et al., 2001; Janovy, 2002; Poulin, 2003; Bagge et al., 2004; Bauer and Whipps, 2013). Realistically, to be a significant factor in structuring the parasite infrapopulations, interactions between parasite species would have to override these ecological forces that distribute parasite species into distinct infracommunities. This situation can only occur under conditions that repeatedly favor co-infections by competitors in the same host over evolutionary time, but parasite infracommunities within hosts are rarely replicated in time and space! Our view is that the rules of assembly for parasite infracommunities is a complicated process that can only be solved by multi-pronged approaches that integrate several levels of biological organization, and this topic will be the subject of most of the remainder of this chapter.

\section{A new paradigm}

Finally, every author acknowledges the key role Holmes played in creating the field of parasite community ecology, often with laudatory prose regarding his experimental methods and analytical savvy, but few have recognized one of the most significant transformations brought about by the Holmes paper-a change in how parasitologists perceive and think about parasites! Small as it may seem, this change was a major paradigm shift without which there would be no study of parasite community ecology. In "Structure of Scientific Revolutions," Kuhn (1962) argued for an episodic model where the pace of normal science is interrupted by periods of revolutionary science. We think that Holmes' (1961) work qualifies for this distinction because after him, parasites became the subject of investigations rather than the object. To answer questions Holmes raised, one had to imagine how the parasites saw their world, and how each individual responded to environmental cues and potential competitors or cooperators (Sukhdeo, 1990).

There was a time when the idea that parasites "behaved" was unimaginable, but after 1961, it became acceptable to wonder how parasites might navigate through their hosts, select mates, or even respond to competitors (Sukhdeo, 1990). Holmes himself explored these ideas by focusing on site specificity as a major factor in structuring parasite communities (Holmes, 1973) and Janovy (2002) argues this is one of the reasons Holmes' 1961 paper has such an enduring quality. However, the shift in tapeworm niche that Holmes reported from co-infections with acanthocephalans turned out to be less than remarkable when it was found out that the tapeworm species in these studies (H. diminuta) had a daily migration up and down the gut (Read and Kilejian, 1969). With the benefit of hindsight, the evidence suggests that the ultimate causation for site or niche specificity is multivariate, and might include competition interactions, physiological or morphological specialization, or mate selection (Holmes, 1973; Sukhdeo, 1990; Rohde, 1991; Sukhdeo and Sukhdeo, 2004).

More importantly, we now recognize that hosts are predictable homeostatic islands that provide a "third environment" that is distinct from free-living aquatic and terrestrial environments (Sukhdeo, 1990). The host environment is so predictable that cestodes, trematodes and nematodes rely on genetically fixed behaviors and strategies to navigate and find their specific sites (Sukhdeo, 1990, 1997, 2000). Navigation through their hosts to find their sites requires complex nervous systems, which are sometimes equivalent or better than their free-living counterparts, with impressive arrays of sensory apparati (Sukhdeo and Mettrick, 1987; Sukhdeo, 1992). As an example, the brain of Fasciola hepatica contains the first evidence of giant neurons and specialized glial cells called trophospongium (adaptations for rapid conduction) that do not appear again until much higher taxa evolved (Sukhdeo et al., 1988a, 1988b; Sukhdeo, 1992). It is interesting that free-living stages of parasites also seem to follow genetically fixed and programmed host-finding behaviors that optimize their transmission across both time and space (Sukhdeo, 1990, 1997; Combes, 2001). Nevertheless, it has become 
increasingly clear that to understand parasite strategies, from the proximate mechanisms of behavior to higher levels of organization in food web structure and ecosystem function, we have to consider the world from the parasite's point of view. It is an evolutionary perspective that drives parasite community ecology today, and this is one of Holmes' most important legacies.

\section{Parasite infracommunities}

We believe that the second major advancement in parasite community ecology was the integration of parasites into mainstream ecological concepts of host communities, mostly occurring over the past 20 years. This period in parasite community ecology is best captured by the most cited paper in The Journal of Parasitology history: Bush et al., (1997) "Parasitology Meets Ecology on its Own Terms: Margolis et al. Revisited." Though not a research article, in its exhaustive detailing of terms to describe patterns in parasite communities for an ecological audience, this paper grappled with a larger issue-how to integrate parasite ecology into mainstream ecological theory, and what form and direction should that integration should take.

Early observational studies to explain patterns in the richness and abundance of observed parasite communities used standard abiotic versus biotic dichotomies: for example, the abundance and diversity of definitive and intermediate hosts (Hoff, 1941; Smith, 2001), along with environmental constraints on transmission (abiotic conditions, e.g., Lafferty, 1997). Unfortunately, many of these studies addressed only a single factor within this mix of factors (e.g., temperature or intermediate host availability) resulting in equivocal results that confounded the underlying processes (Anderson and Sukhdeo, 2013b). Those studies that did focus on the interplay between biotic and abiotic factors on the structure of parasite communities tended to be mathematical, and these have become progressively more complex over time (e.g., Dobson, 1990; Hochberg and Holt, 1990; Greenman and Hudson, 1997, 1999, 2000). A consequence of the theory-driven studies was that general insights into the ecology and evolution of the observed parasite community became obscured. For one, the models were so analytically challenging that the results were often not biologically realistic. In addition, because of specificity of the model systems, there were usually no correlates in biological systems (see review in Keesing et al., 2006). Despite these limitations, the parameters and component processes that are described have enabled parasitologists to connect with community ecologists (e.g., Bush et al., 1997) by generating testable conceptual frameworks that describe parameters thought to be important in parasite establishment and persistence.

Two central concepts have come to define the main paradigm of parasite community ecology, and these tap into two universal evolutionary themes; namely, the basic reproductive rate of an individual, $R_{0}$, and the threshold host population size necessary to sustain a viable population, $N_{T}$ (Anderson, 1982). In their seminal work, Anderson (1982) and Anderson and May (1979, 1982; May and Anderson, 1979) tied the intrinsic rate of population growth, $R_{0}$, to host dynamics using a simple model combining the density of susceptible and infected hosts with transmission rate. In doing so, they revealed how the persistence of an individual parasite population was dependent on the density of hosts. Consequently, a natural extension of the model was the identification of a deterministic criterion for the long term persistence of a parasite species within a host population (Anderson and May, 1991). With this model, it has been possible to generalize criteria for sustained parasite transmission to one biological process: the instantaneous growth rate of parasite infection as a function of host density and proportion of susceptible individuals (Holt and Pickering, 1985; Begon et al., 1992; Holt et al., 2003).

Although this model was based at the population level, the general framework has been and continues to be extended to communities of parasites to identify the general conditions under which host community diversity would alter parasite dynamics (Holt et al., 2003; Dobson, 2004; Rudolf and Antonovics, 2005). These studies have revealed two key features tied to mechanisms of transmission that appears to alter parasite establishment and dynamics: (1) density-, or (2) frequency-dependent transmission whereby the parasite population is a function of the absolute density of the host population, or the proportion of infected hosts within the population (Keesing et al. 2006). Density-dependent models of transmission are typically used to describe parasites that are spread through environmental propagules or random contact (e.g., Gao and Hethcote, 1992). Frequency-dependent 
models are normally used to describe the transmission of sexually transmitted diseases and epidemiology in human systems (see Getz and Pickering, 1983; Thrall et al., 1993). Vector-borne diseases conform broadly to the structure of frequency-dependent models of transmission and theoretical work has demonstrated that contact between vector and host is a function of search rate and infected host density (Antonovics et al., 1995; Rudolf and Antonovics, 2005). It has been argued that if parasite transmission is density-dependent, a more diverse community will result in lower parasite transmission only if the increased diversity reduces the density of the focal host species (Dobson, 2004; Rudolf and Antonovics, 2005). Conversely, in parasites that follow the frequency-dependent mode of transmission, an increase in host community diversity will always result in reduced transmission and establishment success (Dobson, 2004; Rudolf and Antonovics, 2005).

A second consequence of increasing host diversity for metazoan parasites is the potential for transmission success to change depending upon whether the parasite species uses a single- or multi-host life cycle. The assumption that transmission is higher for single-host parasites than for species that rely on multiple hosts is common in almost all models of disease transmission. Begon et al. (1999) and Woolhouse et al. (2001) argue that this assumption is appropriate and a requirement for hosts to coexist in mathematical models. There are only a few examples where multi-host pathogen transmission is higher than single host transmission; importantly, these examples are restricted to a virus (Rhodes et al., 1998) and a bacterium (Caley and Hone, 2004). Evidence suggests that all other metazoan parasites and vector-borne diseases fit the assumption that transmission is higher for single-host parasites (see reviews in Kuris and Lafferty, 2000; Keesing et al., 2006).

Using a simple graphical isocline framework, Holt et al. (2003) further explored the consequences of single- and multi-host pathogen transmission and described a series of critical thresholds for parasites to establish in host communities. In a single-host parasite, the density of the host provides a single threshold to establishment, whereas parasites that use multiple hosts have various combined host densities that enable establishment. Under the assumption that single-host transmission is higher than multi-host transmission, an increase in diversity increases the probability of parasite establishment when compared to lower diversity systems. Furthermore, Holt et al. (2003) demonstrated that increasing the diversity of the system resulted in higher critical host population thresholds; i.e., as the density of a non-target host increases there must be a concomitant increase in the target host density for the parasite to establish - the non-target host dilutes the pool of target hosts (for empirical examples see Norman et al., 1999; Ostfeld and Keesing, 2000; Schmidt and Ostfeld, 2001). In general, additional host species within a system are likely to inhibit the establishment of diverse parasite species because of higher critical thresholds in host density; this may be offset by the higher probability of encountering a target host in more diverse systems, a phenomenon similar to the sampling effect (Loreau et al., 2001).

In spite of the considerable discussion and development of these theoretical frameworks, they have mostly been studied in single-host and single-parasite systems, with the assumption that the observed dynamics scale can be extended to multi-host, multi-parasite communities (Pedersen and Fenton, 2007). This practice stems principally from the difficultly in estimating core parameters such as $R_{0}$ for all parasite species, and the critical host thresholds for all hosts in the system, a necessity given that multiple host-parasite systems are the norm (Anderson and May, 1991). Consequently, over the last 10 years, the literature has detailed a litany of factors, some biotic and others abiotic, that may have an impact upon parasite communities, with no unifying patterns identified (reviewed in Poulin and Morand, 2000). Biotic factors have been demonstrated to drive the dynamics of parasite communities in sea birds (e.g., Bush and Holmes, 1986), and in salmonid and rocky reef fishes (Holmes, 1990; Kennedy and Bush, 1994). In contrast, there are examples where abiotic factors such as "harsh" environmental conditions (Galaktionov, 1996; Marcogliese and Cone, 1996; Biserkov and Kostadinova, 1998; Marcogliese and Pietrock, 2011) and anthropogenic perturbations (Marcogliese, 2001; 2005; Marcogliese and Pietrock, 2011) determine the dynamics of a parasite community. In all cases, successful description of parasite community dynamics within the host environment has relied on local processes with relatively small spatial scales (e.g., Anderson and Sukhdeo, 2010). We assert that by tackling parasite community dynamics on a local scale, parasitologists have gained considerable insight into host factors such as host age and density that may have an impact on parasite community dynamics, but these studies do 
not have the universal appeal of the early population biology studies of Anderson and May (1991).

In contrast to the parasitological focus on fine scale processes that has defined parasite community ecology, mainstream community ecology has explicitly considered community dynamics within a framework consisting of regional and local processes (e.g., Ricklefs and Schluter, 1993; Brown, 1999; Lawton, 1999; Gaston et al., 2000). Although the dominant forces structuring communities varies by system, by including regional processes alongside local processes, ecologists have developed a solid theoretical framework and considerable empirical evidence explaining patterns and processes in many free-living communities. Further, the approach for integrating regional and local processes is frequently in the form of food webs (reviews in Pascual and Dunne, 2005). We contend that it is the "disconnect" between local and regional processes that has stymied parasitologists, and the methods and relative success of community ecology has driven a generation of parasite ecologists to adopt and ask questions in a similar manner, even if they may not be suitable for parasite ecology!

The methods in community ecology were adopted because they were intuitive: regional and local approaches are complementary and were likely to provide important insight into parasite community assembly and diversity patterns. Indeed, the potential benefit of studying parasite community dynamics using multiple scales stems from advances made in the field of complex system analysis (Bar-Yam, 1997; Pascual and Dunne, 2005). This approach suggests that units (molecules, cells, cells with organelles, multicellular organisms, herds, or other organismal groupings) and the relationship between these individual units, may effectively describe system level behaviors. This approach seems particularly useful in parasite study. Recent work has demonstrated the interaction between global environmental change and local parasite dynamics (Harvell et al., 1999) and there is evidence that local transmission dynamics may scale up to affect global disease dynamics (Hahn et al., 2000; Daszak and Cunningham, 2002). It seems plausible to suggest that regional processes coupled with detailed population and community studies, and the relationship between the two scales, will provide more insight into parasite community dynamics than either approach alone.

\section{Parasites and food webs}

Though not immediately obvious, this "complex system" approach has been used in mainstream ecology since the work of Charles Elton in the 1920s (Elton, 1927). This approach describes trophic interactions between consumers and resources which, in effect, unifies local and regional dynamics. Local interactions between species-trophic links-are in part determined by regional dynamics for two reasons: resource competition and energy. The topology of webs and the interactions within them influence the dynamics and persistence of populations through resource availability and mortality caused by predation (De Ruiter et al., 2005; Pascual and Dunne, 2005; Neutel et al., 2007). Moreover, trophic interactions represent transfer rates of energy and matter, a fundamental concept in ecosystem and community processes. Food webs, therefore, provide a way to analyze the relationship between populations, communities, and ecosystems and core ecological concepts such as stability, diversity, and community assembly (Sukhdeo and Hernandez, 2005; Lafferty et al., 2008; Anderson and Sukhdeo, 2013a).

The use of food web analysis to reveal underlying concepts in parasite ecology has exploded following Marcogliese and Cone's call to arms in the late 1990s. Nevertheless, there are still only a small number of food webs in the literature that contain parasites (e.g., Lafferty et al., 2006b; Anderson and Sukhdeo, 2011; Preston et al., 2013). The lack of taxonomic resolution and inclusion of parasites in food web descriptions and theory is a major criticism leveled at food web ecology (Huxham et al., 1995; Marcogliese and Cone, 1997). Frequently, published webs include relatively few of the species present in the system; further, they rarely describe all the potential interactions. The most common consumer strategy, parasitism, is generally left out of food web analyses (Lafferty and Kuris, 2002). Given the difficulty quantifying parasite-host interactions using standard ecological techniques this situation is not surprising, yet parasitism appears to be a fundamental feature of all natural systems. Price (1980) estimates that parasitism is a strategy used by over $50 \%$ of all species at some point in their life history. Esch and Fernandez (1993) make the claim that the number of non-parasitic species that are parasitized approaches $100 \%$. Similarly Rohde (1993b) suggests that all marine 
species are infected with parasites. Despite the obvious ubiquitous nature of parasitism, there remain few food webs in the literature that contain metazoan parasites (Huxham et al., 1995; Lafferty et al., 2006b; Hernandez and Sukhdeo, 2008; Mouritsen et al., 2011; Thieltges et al., 2011; Preston et al., 2012), and those that are included represent a small fraction of possible species and potential trophic links likely to be present. In some cases, there is acknowledgement of the omission of parasites from community webs, but the diverse sizes and feeding strategies used by parasites make it very difficult to retrofit them into the 50 years of food web theory.

It is possible to construct food webs anew including parasites (e.g., Lafferty et al., 2006b) or add parasite information to existing food webs using parasite-host records (e.g., Anderson and Sukhdeo, 2011). Despite the promise of this approach, it is a non-trivial pursuit that should be embarked upon with caution. Systematic inclusion and consideration of all parasites for all free-living species in food webs would be ideal but it is clearly intractable to include all species in a system. Further, not all food web datasets are appropriate for expansion to include parasites because of the high degree of taxonomic aggregation, i.e., functional groups, whereas others are dominated by species with few historical parasite-host records. Consequently, including parasites in food webs and understanding how they impact upon food web dynamics and topology can result in exhaustive multi-year empirical studies (Hernandez and Sukhdeo, 2008; Kuris et al., 2008). Further, integrating parasites has generally taken the approach of developing a parasite subweb (sensu Lafferty et al., 2006a) which does not take into account the delightfully elegant complexities of trophically transmitted parasites (Sukhdeo, 2012). Including parasites then seems to run counter to the initial goal of food web analyses: the description of complex multi-scale processes in simple webs that provide insight into patterns and processes. Consequently, a more fruitful question may then be what can host food webs and community ecology tell us about parasites?

For several decades a dominant paradigm in community ecology was that complex communities are more stable than simple ones (MacArthur, 1955; Hutchinson, 1959; Elton, 2000). MacArthur (1955) postulated that a large number of "paths" through each species is necessary to ameliorate the effects of dominant or overpopulated species. He concluded that "stability increases as the number of links increases," tying together the concept of community stability with two core food web properties, trophic linkage and number of species. May (1972, 1973) challenged this general paradigm using dynamic models of abstract communities, finding that communities tended towards unstable behavior as system complexity increased. He made the observation that stability in food webs is conditional on the interaction between species diversity $(S)$, connectance between species $(C)$, and interaction strength $(i)$ and that systems would be stable if $i(S C)^{1 / 2}<1$. Several papers since May $(1972,1973)$ have pointed out the limitations in his analyses of abstract communities (e.g., Lawlor, 1980; Cohen and Newman, 1985; Polis, 1991), stemming largely from evidence suggesting that species interactions in biological systems are not random. Regardless, May's work provided a framework to empirically address two universal parameters: the interplay between diversity and connectance and the ratio of species to links within the food web (linkage density).

The core metric in much of this discussion, connectance $C$, has not been ignored by parasite ecologists. Fundamentally, $C$ measures the proportion of potential links among species that are realized, and it is predicted to decrease hyperbolically as species richness increases to maintain system stability (Warren, 1989; Dunne, 2006). Original analyses of community dynamics using $C$ provoked a flurry of criticism because they included only a fraction of species present in natural systems (Paine, 1988; Polis, 1991; Hall and Raffaelli, 1993). However, subsequent analyses of food webs with higher taxonomic resolution detailed how an increase in species, including parasite links, resulted in a decrease in connectance fitting the community ecology paradigm (Huxham et al., 1995; Memmott et al., 2000; Thompson et al., 2005). And it was then that parasitologists became a focal point in the debate. Lafferty and colleagues (Lafferty et al., 2006a) re-analyzed these data along with other parasite-host webs and documented that a startling number of food-web links are parasite derived. Further, by omitting illogical parasite-parasite and predator-parasite links from analysis and they found an increase in connectance. These data do not fit the expected inverse relationship between connectance and species diversity and created a conundrum for parasite ecologists: a food web with parasites is not unstable! Post-hoc explanations such as suggesting that increased web cohesiveness offset the increase species 
richness and concomitant increase in connectance were proposed (Lafferty et al. 2006a, 2006b), but were relatively underwhelming because the metrics used in these arguments were derived from topological matrices rather than biological observation.

A more plausible explanation is that the true biology of parasites with complex life cycles solves the apparent paradox of a diverse, highly connected communities retaining stability. A major impact of including parasites in food web analyses is the extension of trophic chains (Williams and Martinez, 2004), which should decrease system stability. However, complex life cycle parasites, though extending the length of trophic chains, introduce relatively weak interactions into "long loops" that may offset the effect of increasing connectance (Neutel et al., 2002). Many parasitic helminths with complex life cycles have strong impacts on some species in their life cycle (e.g., Lafferty and Morris, 1996) but have weak or non-detectable impacts on others. Further, when parasitic helminths infect intermediate hosts in their life cycle, they parasitize a small fraction of the total population of that host and a smaller fraction of that goes on to infect the next host in the life cycle. A consequence of this situation is that the interaction link between a parasite and host is a relatively weak one (Dobson et al., 2006). Additionally, direct life cycle parasites may be a strong stabilizing force because their dynamics are typically frequency dependent and the most common host species may suffer the greatest pathology (Dobson, 2004; Lafferty et al., 2008). Though the net effect of including parasites in food webs is an increase in species diversity and an increase in connectance that would seemingly result in lower system stability, any effects may be offset by relatively weak links with a significant number of free-living species on multiple trophic levels (Neutel et al. 2002; Dobson et al. 2006). This narrative reveals a critical component of our thesis: incorporating an evolutionary perspective of parasitism reveals a potentially fundamental, though untested, property in community ecology-parasites may be the glue that binds food webs together!

Considerable effort has gone into explaining food web regularities beyond diversity and the distribution and density of feeding links between species (see reviews in (Belgrano, 2005; Pascual and Dunne, 2005). Beginning in the early 2000s, a series of studies in community ecology began to apply analytical methods derived from graph theory. Specifically these researchers began to search for regular patterns of species interactions within ecological communities (Dunne 2006). Montoya and Sole (2002) used three empirical food webs and found that web topology was very similar to those of small world, scale-free networks like the World Wide Web. Contradicting these results was a meta-analysis conducted on seven food webs by Camacho et al. (2002) who found that the degree of clustering in empirical food webs was no higher than would be expected from random expectations, and significantly lower than clustering in small world networks. In an attempt to bridge this conflict, Dunne et al. (2002) expanded analysis to 16 food webs, including those used by Montoya and Sole (2002) and Camacho et al. (2002), and concluded that most food webs displayed low clustering coefficients and link distributions that deviated from those of scale-free networks.

Although these studies may appear to be esoteric mathematical explorations, the implication derived from them is that food webs deviate from physical networks and are not randomly connected "graphs" or regular lattices in which every species has the same number and pattern of links. Instead, the majority of food webs seem to have a unique topology, one that has relatively low diversity, high connectance, a degree distribution that is exponential in form and a short path length between species. That is, within a food web there are a few highly connected species that give the appearance of compartments in webs. Given the partial reliance of parasites on trophic interactions for the successful completion of their life cycles, we would expect these free-living regularities to be reflected in subsequent patterns of parasite diversity observed in extant systems (Marcogliese, 2003).

The search for tightly interacting compartments in food webs, however, has presented conflicting accounts of their presence (e.g., Paine, 1966) or absence (Pimm and Lawton, 1980). We think it likely that this conflict is likely caused by analytical difficulties: high connectance, a trait of most food webs, may obscure the presence of compartments. Recent methodological advances have provided a variety of effective algorithms that identify compartments by searching for nestedness, modularity, or "groups." Particularly relevant for parasites is the presence of clusters of species that may be core components of the food web network. Intuitively, host species that are central within ecological networks experience fewer fluctuations in abundance relative to those that 
fall in the periphery of a network providing a reliable resource for parasites. Second, stable ecological interactions between predators and prey may ensure successful completion of the parasite life cycle, and this dynamic will be represented by clusters of tightly interacting species that form the mathematical foundation for food web nestedness and modularity.

These characteristics will be particularly important for helminth parasites with complex life cycles involving two or more hosts where transmission occurs via predation. The reliance on this form of transmission, over evolutionary time, is likely to have favored parasitism of host species that are central to the structure of food webs, and fall within interactions that are relatively "strong" (Anderson and Sukhdeo, 2011, 2013a). Using this logic, parasite ecologists have been able to identifying patterns in the topology of ecological networks and link these regularities in the networks to parasite community dynamics (Chen et al., 2008; Anderson and Sukhdeo, 2011). The argument has been that a reliable and stable source of energy is required for the persistence over evolutionary time (Anderson, 2009; Anderson and Sukhdeo, 2010, 2013a).

These data have allowed the parasite ecology community to rephrase the discussion towards asking what the parasite needs to survive and reproduce, rather than what the parasite is doing to the host. This approach is similar to the metabolic theory of ecology (Brown et al., 2004), which proposes that energy metabolism is the central unifying theme in ecology. Remarkably, Hechinger and colleagues (Hechinger et al., 2011a) applied this framework to parasite and free-living species and were able to demonstrate that biomass production within trophic levels was invariant of body size across all species and functional groups! The critical implication is that the flow of energy to parasites operates under the same thermodynamic rules that govern energy flows to every organism in the food web (Sukhdeo and Hernandez, 2005; Sukhdeo, 2010). Indeed, thinking of parasites as energy-limited may explain disparate results such as highly diverse salt marsh systems in California (Hechinger and Lafferty, 2005) and Chilean intertidal zones (Hechinger et al., 2008) supporting a high diversity of parasites, whereas a comparable salt marsh system in New Jersey documented no such association (Anderson and Sukhdeo, 2013b). Parasites have high host fidelity, and there should be a correlation between the success of establishment in a specific host population and the local stability of that community. Logically, a community that is locally stable (Ives and Carpenter, 2007; Allesina and Tang, 2012) represents a predictable resource for complex life cycle parasites to establish in or upon. Thompson et al. (2013) were able to track energetic resources through a food web and find patterns that suggested a relationship between energy flow and parasite community dynamics and diversity. Anderson (2009) and Anderson and Sukhdeo (2013a) used a qualitative measure of community stability as a proxy of energy flow and were able to document a positive correlation between system stability and parasite community assembly. And perhaps more convincingly, Sukhdeo (2012) and Rossiter (2012) presented data documenting biomass fluctuation over time in a New Jersey river, and were able to show that parasites preferred hosts that were the most stable in their seasonal biomass values, clearly supporting the idea that reliable and stable energetic resources are an important component for parasitism. This observation clearly represents a success: mainstream ecological theory has provided insight into parasite community ecology-but is this an exception?

\section{Final comments}

Despite the increasing attention parasites have received over the past decade, and the successes we have documented earlier, our understanding of parasite community assembly mechanisms remains rudimentary. Generally the establishment of parasites in host systems has not been explored beyond epidemiological settings and the invasion of novel environments (e.g., Kennedy, 1990; Kennedy and Fitch, 1990). Intuitively, the absence of necessary host resources will be reflected in the absence of parasite species (Hudson et al., 2006). And similarly, it is plausible to suggest that presence of a diverse parasite community reflects the presence of a diverse host community; not only definitive species but also all species involved in the functioning of the free-living community (Anderson and Sukhdeo, 2010). We suggest that a necessary part of host-parasite community ecology is the study of all links, and the distribution of these links, in the network of host-host and host-parasite interactions and how patterns of energy flow underlay all of these dynamics! A simple task, no doubt, but given the wealth of food web theory 
(see reviews in De Ruiter et al., 2005; Pascual and Dunne 2006) describing community regularities, and the tight evolutionary link between host and parasite, there are likely predictable structures within the host food web that facilitate establishment and persistence of parasites: a framework that considers each of these steps, from a parasite's perspective is hopefully in our future (Fig. 3).

This chapter is a preliminary step towards synthesizing an almost overwhelming number of studies that have been conducted on parasite community ecology over the past 100 years. As we reflect on the development of the field, we realize that we are only at the start of the journey towards understanding of how parasites establish and persist within ecological communities. There have been elegant experimental demonstrations of parasite interactions or lack thereof, observational descriptions of how free-living species diversity and dynamics and the transmission environment determines parasite community dynamics or does not, and how modern ecological theory-primarily in the field of food web ecology - is a poor fit for what we know of the biology of parasites unless filtered through an evolutionary perspective. After Holmes' seminal experimental, our approach was to shoehorn ideas from the community ecologists, and to try to force these ideas (especially regarding competition) on to parasites. We continued to do this at the community level, and now parasites are mired as a "pseudonode" within food webs, despite the demonstration of their critical importance in modifying energy flow and species interactions. Our future history will be to disentangle parasites from the theoretical mess, and to strike out on our own. It is an evolutionary perspective which drives parasite community ecology today, and this is one of most important legacies of the early papers in The Journal of Parasitology: if you understand how your parasite perceives and responds to its world, you can truly make a contribution to our understanding of parasite community ecology.

\section{Acknowledgments}

We are grateful for the opportunity provided by John Janovy, Jr and Gerald Esch to read and comment on a century of parasite community ecology. MVKS was funded by USDA Hatch grants and the Rutgers
University Parasite Research Fund. TKA was funded by a Georgia Southern University Faculty Development Grant and would like to acknowledge his friend and mentor who is no longer here-Ian D. Whittington-for his generosity, for sharing countless cups of coffee, for his encouragement and support, and for fatefully providing a MVKS paper to read during his undergraduate studies that moved him into the world of parasite community ecology.

\section{Literature cited}

Allesina, S., and S. Tang. 2012. Stability criteria for complex ecosystems. Nature 483: 205-208.

Anderson, R. M. 1982. Population dynamics of infectious diseases: theory and applications. Chapman and Hall, London, U.K., 368 p.

, and R. May. 1982. Coevolution of hosts and parasites. Parasitology 85: 411-426. and 1979. Population biology of infectious diseases: Part I. Nature 280: 361-367. and 1991. Infectious diseases of humans. Oxford University Press, Oxford, U.K., 768 p.

Anderson, T. K. 2009. Food web networks and parasite diversity. Ph.D. Thesis, Rutgers University, New Brunswick, New Jersey, $185 \mathrm{p}$. and M. V. K. Sukhdeo. 2010. Abiotic versus biotic hierarchies in the assembly of parasite populations. Parasitology 137: 743-754. , and 2011 . Host centrality in food web networks determines parasite diversity. PLoS One 6: e26798. , and 2013a. Qualitative community stability determines parasite establishment and richness in estuarine marshes. Peer J 1: e92. , and .2013b. The relationship between community species richness and the richness of the parasite community in Fundulus heteroclitus. Journal of Parasitology 99: 391-396.

Antonovics, J., Y. Iwasa, and M. P. Hassell. 1995. A generalized model of parasitoid, venereal, and vector-based transmission processes. American Naturalist 145: 661-675.

Bagge, A. M., R. Poulin, and E. T. Valtonen. 2004. Fish population size, and not density, as the determining factor of parasite infection: a case study. Parasitology 128: 305-313.

Bansemir, A. D., and M. V. K. Sukhdeo. 2001. Intestinal distribution of worms and host ingesta in Nippostrongylus brasiliensis. Journal of Parasitology 87: 1470-1472.

Bar-Yam, Y. 1997. Dynamics of complex systems. Westview Press, Boston, $864 \mathrm{p}$.

Bauer, E. F., and C. M. Whipps. 2013. Parasites of two native fishes in adjacent Adirondack Lakes. Journal of Parasitology 99: 603-609. 
Begon, M., R. G. Bowers, N. Kadianakis, and D. E. Hodgkinson. 1992. Disease and community structure: The importance of host self-regulation in a host-host-pathogen model. American Naturalist 139: 1131-1150.

Begon, M., S. M. Hazel, D. Baxby, K. Bown, R. Cavanagh, J. Chantrey, T. Jones, and M. Bennett. 1999. Transmission dynamics of a zoonotic pathogen within and between wildlife host species. Proceedings of the Royal Society of London: Series B 266: 1939-1945.

Belgrano, A. 2005. Aquatic food webs: An ecosystem approach. Oxford University Press, Oxford, 272 p.

Biserkov, V., and A. Kostadinova. 1998. Intestinal helminth communities in the green lizard, Lacerta viridis, from Bulgaria. Journal of Helminthology 72: 267-271.

Brown, J. H. 1999. Macroecology: Progress and prospect. Oikos 87: $3-14$

J. Gillooly, A. Allen, V. Savage, and G. West. 2004. Toward a metabolic theory of ecology. Ecology 85 : $1771-1789$.

Bucknell, D., H. Hoste, R. B. Gasser, and I. Beveridge. 1996. The structure of the community of strongyloid nematodes of domestic equids. Journal of Helminthology 70: 185-192.

Bush, A. O., and J.C. Holmes. 1986. Intestinal helminths of lesser scaup ducks: An interactive community. Canadian Journal of Zoology 64: 142-152.

K. D. Lafferty, J. M. Lotz, and A. W. Shostak. 1997. Parasitology meets ecology on its own terms: Margolis et al. revisited. Journal of Parasitology 83: 575-583.

Cabaret, J., and H. Hoste. 1998. Comparative analysis of two methods used to show interspecific associations in naturally acquired parasite nematode communities from the abomasum of ewes. Veterinary Parasitology 76: 275-285.

Caley, P., and J. Hone. 2004. Disease transmission between and within species, and the implications for disease control. Journal of Applied Ecology 41: 94-104.

Camacho, J., R. Guimerà, and L. A. N. Amaral. 2002. Robust patterns in food web structure. Physical Review Letters 88 : 228102.

Chandler, A. C. 1939. The effects of number and age of worms on development of primary and secondary infections with Hymenolepis diminuta in rats, and an investigation into the true nature of "premunition" in tapeworm infections. American Journal of Epidemiology 29: 105-114.

Chen, H.-W., W. -C. Liu, A.J. Davis, F. Jordan, M. -J. Hwang, and K. -T. Shao. 2008. Network position of hosts in food webs and their parasite diversity. Oikos 117: 1847-1855.

Cohen, J. E., and C. M. Newman. 1985. When will a large complex system be stable? Journal of Theoretical Biology 113: 153-156.

Combes, C. 2001. Parasitism: The ecology and evolution of intimate interactions. University of Chicago Press, Chicago, I.L., $552 \mathrm{p}$.

Cox, F. E. 2001. Concomitant infections, parasites and immune responses. Parasitology 122: S23-38.
Crofton, H. D. 1971. A model of host-parasite relationships. Parasitology 63: 343-364.

Cross, S. X. 1934. A probable case of non-specific immunity between two parasites of ciscoes of the Trout Lake region of northern Wisconsin. Journal of Parasitology 20: 244-245.

Curtis, L. A. 1997. Ilyanassa obsoleta gastropoda as a host for trematodes in Delaware estuaries. Journal of Parasitology 83: $793-803$.

and K. M. Hubbard. 1993. Species relationships in a marine gastropod-trematode ecological system. The Biological Bulletin 184: 25-35.

Daszak, P., and A. A. Cunningham. 2002. Emerging infectious diseases: A key role for conservation medicine. In Conservation medicine: Ecological health in practice, A. A. Aguirre, R. S. Ostfeld, G. M. Taylor, C. House, and M. C. Pearl (eds.). Oxford University Press, Oxford, U.K., p. 40-61.

De Ruiter, P. C., V. Wolters, J. C. Moore, and K. O. Winemiller. 2005. Food web ecology: Playing Jenga and beyond. Science 309: $68-71$.

Dobson, A. P. 1990. Models for multi-species parasite-host communities. In Parasite communities: Patterns and processes, G. W. Esch, A. O. Bush, and J. M. Aho (eds.). Springer, The Netherlands, p. 261-288. 2004. Population dynamics of pathogens with multiple host species. American Naturalist 164: S64-78. and S.W. Pacala. 1992. The parasites of Anolis lizards the northern Lesser Antilles. II. The structure of the parasite community. Oecologia 92: 118-125.

Dobson, A. P., K. D. Lafferty, and A. M. Kuris. 2006. Parasites and food webs. In Ecological networks: Linking structure to dynamics in food webs, M. Pascual, and J. A. Dunne (eds.). Oxford University Press, Oxford, U.K., p. 119-135.

Dove, A. D. 1999. A new index of interactivity in parasite communities. International Journal for Parasitology 29: 915-920.

Dunne, J. A. 2006. The network structure of food webs. In Ecological networks: Linking structure to dynamics in food webs, M. Pascual, and J. A. Dunne (eds.). Oxford University Press, Oxford, U.K., p. 27-86.

R. J. Williams, and N. D. Martinez. 2002. Food-web structure and network theory: The role of connectance and size. Proceedings of the National Academy of Sciences of the United States of America 99: 12917-12922.

Elton, C. S. 1927. Animal ecology. University of Chicago Press, Chicago, I.L., 296 p. 2000. The ecology of invasions by animals and plants. University of Chicago Press, Chicago, I.L., 196 p.

Esch, G. W., and J. C. Fernandez. 1993. A functional biology of parasitism: Ecological and evolutionary implications. Chapman and Hall, London, U.K., 337 p. and 1994. Snail-trematode interactions and parasite community dynamics in aquatic systems: A review. The American Midland Naturalist 131: 209-237. 
Bush, A. O. and Aho, J. M. 1990a. Parasite communities: patterns and processes. Chapman and Hall, London, U.K., 335 p.

C. R. Kennedy, A. O. Bush, and J. M. Aho. 1988. Patterns in helminth communities in freshwater fish in Great Britain: Alternative strategies for colonization. Parasitology 96: 519-532.

A. W. Shostak, D. J. Marcogliese, and T. M. Goater. 1990b. Patterns and processes in helminth parasite communities: an overview. In Parasite communities: patterns and processes, G. W. Esch, A. O. Bush, and J. M. Aho (eds.). Springer, The Netherlands, p. 1-19.

E. J. Wetzel, D. A. Zelmer, and A. M. Schotthoefer. 1997. Long-term changes in parasite population and community structure: A case history. The American Midland Naturalist 137: 369-387.

Fernandez, J. C., and G.W. Esch. 1991a. Guild structure of larval trematodes in the snail Helisoma anceps: Patterns and processes at the individual host level. Journal of Parasitology 77: $528-539$.

and 1991b. The component community structure of larval trematodes in the pulmonate snail Helisoma anceps. Journal of Parasitology 77: 540-550.

Fredensborg, B. L., and R. Poulin. 2005. Larval helminths in intermediate hosts: Does competition early in life determine the fitness of adult parasites? International Journal for Parasitology 35: 1061-1070.

Galaktionov, K. V. 1996. Life cycles and distribution of seabird helminths in arctic and sub-arctic regions. Bulletin of the Scandinavian Society of Parasitology 6: 31-49.

Gao, L. Q., and Hethcote, H. W. 1992. Disease transmission models with density-dependent demographics. Journal of Mathematical Biology 30: 717-731.

Gaston, K. J., T. M. Blackburn, J. J. Greenwood, R. D. Gregory, R. M. Quinn, and J. H. Lawton. 2000. Abundance-occupancy relationships. Journal of Applied Ecology 37: 39-59.

Gause, G. F. 1932. Experimental studies on the struggle for existence I. Mixed population of two species of yeast. Journal of Experimental Biology 9: 389-402.

Getz, W. M., and J. Pickering, J. 1983. Epidemic models: Thresholds and population regulation. American Naturalist 121: 892-898.

Goater, T. M., G. W. Esch, and A. O. Bush. 1987. Helminth parasites of sympatric salamanders: Ecological concepts at infracommunity, component and compound community levels. The American Midland Naturalist 118: 289-300.

Greenman, J. V., and P. J. Hudson. 1997. Infected coexistence instability with and without density-dependent regulation. Journal of Theoretical Biology 185: 345-356. and 1999. Host exclusion and coexistence in apparent and direct competition: An application of bifurcation theory. Theoretical Population Biology 56: 48-64. and 2000. Parasite-mediated and direct competition in a two-host shared macroparasite system. Theoretical Population Biology 57: 13-34.

Hager, A. 1941. Effects of dietary modifications on the tapeworm Hymenolepis diminuta. Iowa State Journal of Research 16: 60.

Hahn, B. H., G. M. Shaw, K. M. De, and P. M. Sharp. 2000. AIDS as a zoonosis: Scientific and public health implications. Science 287: 607-614.

Hall, S. J., and D. G. Raffaelli. 1993. Food webs: Theory and reality. Advances in Ecological Research 24: 187-239.

Harvell, C., K. Kim, J. Burkholder, R. Colwell, P. Epstein, D. Grimes, E. Hofmann, E. Lipp, A. Osterhaus, R. Overstreet, et al. 1999. Emerging marine diseases-Climate links and anthropogenic factors. Science 285: 1505-1510.

Hechinger, R. F., and K. D. Lafferty. 2005. Host diversity begets parasite diversity: Bird final hosts and trematodes in snail intermediate hosts. Proceedings of the Royal Society of London: Series B 272: 1059-1066.

and A. M. Kuris. 2008. Trematodes indicate animal biodiversity in the Chilean intertidal and Lake Tanganyika. Journal of Parasitology 94: 966-968.

A. P. Dobson, J. H. Brown, and A. M. Kuris.

2011 a. A common scaling rule for abundance, energetics, and production of parasitic and free-living species. Science 333 : 445-448.

A. C. Wood, and A. M. Kuris. 2011 b. Social organization in a flatworm: Trematode parasites form soldier and reproductive castes. Proceedings of the Royal Society of London: Series B 278: 656-665.

Heins, D. C., J. A. Baker, M. A. Toups, and E. L. Birden. 2010. Evolutionary significance of fecundity reduction in threespine stickleback infected by the diphyllobothriidean cestode Schistocephalus solidus. Biological Journal of the Linnean Society 100: 835-846.

Hernandez, A. D. and Sukhdeo, M. V. K. 2008. Parasites alter the topology of a stream food web across seasons. Oecologia 156: 613-624.

Hochberg, M., and R. Holt. 1990. The coexistence of competing parasites. I. The role of cross-species infection. American Naturalist 136: 517-541.

Hoff, C. C. 1941. A case of correlation between infection of snail hosts with Cryptocotyle lingua and the habits of gulls. Journal of Parasitology 27: 539-539.

Holmes, J. C. 1961. Effects of concurrent infections on Hymenolepis diminuta Cestoda and Moniliformis dubius Acanthocephala. I. General effects and comparison with crowding. Journal of Parasitology 47: 209.

1962a. Effects of concurrent infections on Hymenolepis diminuta Cestoda and Moniliformis dubius Acanthocephala. III. Effects in hamsters. Journal of Parasitology 48: 97-100. 1962b. Effects of concurrent infections on Hymenolepis diminuta Cestoda and Moniliformis dubius Acanthocephala. II. Effects on growth. Journal of Parasitology 48: 87-96. 
1973. Site selection by parasitic helminths: Interspecific interactions, site segregation, and their importance to the development of helminth communities. Canadian Journal of Zoology 51: 333-347.

1990. Helminth communities in marine fishes. In Parasite communities: Patterns and processes, G. W. Esch, A. O. Bush, and J. M. Aho (eds.). Springer, The Netherlands, p. $101-130$

and P.W. Price. 1986. Communities of parasites. In Community ecology: Pattern and process, J. Kikkawa, and D. J. Anderson (eds.). Blackwell Publishing, Oxford, U.K., p. $187-213$.

Holt, R. D., and J. Pickering. 1985. Infectious disease and species coexistence: A model of Lotka-Volterra form. American Naturalist 126: 196-211.

A. P. Dobson, M. Begon, R. Bowers, and E. Schauber. 2003. Parasite establishment in host communities. Ecology Letters 6: 837-842.

Hudson, P. J., A. P. Dobson, and K. D. Lafferty. 2006. Is a healthy ecosystem one that is rich in parasites? Trends In Ecology $\delta$ Evolution 21: 381-385.

Hunninen, A. V. 1935. Studies on the life history and host-parasite relations of Hymenolepis fraterna (H. nana, var. fraterna, Stiles) in white mice. American Journal of Epidemiology 22: 414-443.

Hutchinson, G. 1959. Homage to Santa Rosalia or why are there so many kinds of animals? American Naturalist 93: 145-159.

Huxham, M., D. Raffaelli, and A. Pike. 1995. Parasites and food web patterns. Journal of Animal Ecology 64: 168-176.

Ives, A. R., and S. R. Carpenter. 2007. Stability and diversity of ecosystems. Science 317: 58-62.

Janovy, Jr, J. 2002. Concurrent infections and the community ecology of helminth parasites. Journal of Parasitology $\mathbf{8 8}$ : 440-445.

Keesing, F., R. D. Holt, and R. S. Ostfeld. 2006. Effects of species diversity on disease risk. Ecology Letters 9: 485-498.

Kennedy, C. R. 1990. Helminth communities in freshwater fish: Structured communities or stochastic assemblages? In Parasite communities: Patterns and processes, G. W. Esch, A. O. Bush, and J. M. Aho (eds.). Springer, The Netherlands, p. $131-156$

and A. O. Bush. 1994. The relationship between pattern and scale in parasite communities: A stranger in a strange land. Parasitology 109: 187-196.

and D. J. Fitch. 1990. Colonization, larval survival and epidemiology of the nematode Anguillicola crassus, parasitic in the eel, Anguilla anguilla, in Britain. Journal of Fish Biology 36: 117-131.

Kuhn, T. S. 1962. The structure of scientific revolutions. University of Chicago Press, Chicago, I.L., 172 p.

Kuris, A. M., and K. D. Lafferty. 2000. Parasite-host modeling meets reality: Adaptive peaks and their ecological attributes. In Evolutionary biology of host-parasite relationships: Theory meets reality, R. Poulin, S. Morand, A. Skorping (eds.). Elsevier Science, New York, N.Y., p. 9-26.
R. F. Hechinger, J. C. Shaw, K. L. Whitney, L. Aguirre-Macedo, C. A. Boch, A. P. Dobson, E. J. Dunham, B. L. Fredensborg, T. C. Huspeni, et al. 2008. Ecosystem energetic implications of parasite and free-living biomass in three estuaries. Nature 454: 515-518.

Lafferty, K. and Morris, A. 1996. Altered behavior of parasitized killifish increases susceptibility to predation by bird final hosts. Ecology 77: 1390-1397.

1997. Environmental parasitology: What can parasites tell us about human impacts on the environment? Parasitology Today 13: 251-255.

1999. The evolution of trophic transmission. Parasitology Today 15: 111-115.

and A. M. Kuris. 2002. Trophic strategies, animal diversity and body size. Trends in Ecology \& Evolution 17: 507-513.

S. Allesina, M. Arim, C. J. Briggs, G. De Leo, A. P. Dobson, J. A. Dunne, P. T. J. Johnson, A. M. Kuris, D. J. Marcogliese, et al. 2008. Parasites in food webs: The ultimate missing links. Ecology Letters 11: 533-546.

A. P. Dobson, and A. M. Kuris. 2006a. Parasites dominate food web links. Proceedings of the National Academy of Sciences of the United States of America 103: 11211-11216.

R. F. Hechinger, and J. C. Shaw. 2006b. Food webs and parasites in a salt marsh ecosystem. In Disease ecology: Community structure and pathogen dynamics, S. K. Collinge, and C. Ray (eds.). Oxford University Press, Oxford, U.K., p. $119-134$

Lawlor, L. 1980. Structure and stability in natural and randomly constructed competitive communities. American Naturalist 116: 394-408.

Lawton, J. 1999. Are there general laws in ecology? Oikos 84: 177-192.

Loreau, M., S. Naeem, P. Inchausti, J. Bengtsson, J. Grime, A. Hector, D. Hooper, M. Huston, D. Raffaelli, B. Schmid, et al. 2001. Biodiversity and ecosystem functioning: Current knowledge and future challenges. Science 294: 804-808.

Lotka, A. J. 1925. Elements of physical biology. Plenum Press, New York, N.Y., 492 p.

Lotz, J. M., and W. F. Font. 1994. Excess positive associations in communities of intestinal helminths of bats: A refined null hypothesis and a test of the facilitation hypothesis. Journal of Parasitology 80: 398-413.

Luque, J., D. Mouillot, and R. Poulin. 2004. Parasite biodiversity and its determinants in coastal marine teleost fishes of Brazil. Parasitology 128: 671-682.

MacArthur, R. 1955. Fluctuations of animal populations and a measure of community stability. Ecology 36: 533-536.

Marcogliese, D. J., and D. K. Cone, 1997. Food webs: A plea for parasites. Trends In Ecology \& Evolution 12: 320-325. 2003. Food webs and biodiversity: Are parasites the missing link? Journal of Parasitology 89: S106-113. 2001. Implications of climate change for parasitism of animals in the aquatic environment. Canadian Journal of Zoology 79: 1331-1352. 
2005. Parasites of the superorganism: Are they indicators of ecosystem health? International Journal for Parasitology 35: 705-716.

and D. K. Cone. 1996. On the distribution and abundance of eel parasites in Nova Scotia: Influence of pH. Journal of Parasitology 82: 389-399.

and M. Pietrock. 2011. Combined effects of parasites and contaminants on animal health: Parasites do matter. Trends in Parasitology 27: 123-130.

May, R. M. 1972. Will a large complex system be stable? Nature 238: 413-414.

1973. Stability and complexity in model ecosystems. Princeton University Press, Princeton, N.J., 304 p.

and R. M. Anderson. 1979. Population biology of infectious diseases: Part II. Nature 280: 455-461.

Memmott, J., N. Martinez, and J. Cohen. 2000. Predators, parasitoids and pathogens: Species richness, trophic generality and body sizes in a natural food web. Journal of Animal Ecology 69: 1-15.

Montoya, J. M., and R. V. Solé. 2002. Small world patterns in food webs. Journal of Theoretical Biology 214: 405-412.

Mouritsen, K. N., R. Poulin, J. P. McLaughlin, and D. W. Thieltges. 2011. Food web including metazoan parasites for an intertidal ecosystem in New Zealand: Ecological Archives E092-173. Ecology 92: 2006-2006.

Neuhäuser, M., and R. Poulin. 2004. Comparing parasite numbers between samples of hosts. Journal of Parasitology $\mathbf{9 0 :}$ 689-691.

Neutel, A.-M., J. A. P. Heesterbeek, and P. C. De Ruiter. 2002. Stability in real food webs: Weak links in long loops. Science 296: $1120-1123$.

, J. A. P. Heesterbeek, J. van de Koppel, G. Hoenderboom, A. Vos, C. Kaldeway, F. Berendse, and P. C. De Ruiter. 2007. Reconciling complexity with stability in naturally assembling food webs. Nature 449: 599-602.

Nolf, L. O., and W. W. Cort. 1933. On immunity reactions of snails to the penetration of the cercariae of the strigeid trematode, Cotylurus flabelliformis Faust. Journal of Parasitology 20: 38-48.

Norman, R., R. G. Bowers, M. Begon, and P. J. Hudson. 1999. Persistence of tick-borne virus in the presence of multiple host species: Tick reservoirs and parasite mediated competition. Journal of Theoretical Biology 200: 111-118.

Ostfeld, R., and F. Keesing. 2000. Biodiversity and disease risk: The case of lyme disease. Conservation Biology 14: 722-728.

Paine, R. 1988. Road maps of interactions or grist for theoretical development? Ecology 69: 1648-1654.

1966. Food web complexity and species diversity. American Naturalist 100: 65-75.

Pascual, M., and J. A. Dunne. 2005. Ecological networks: Linking structure to dynamics in food webs. Oxford University Press, Oxford, U.K., 416 p.

Pedersen, A. B., and A. Fenton. 2007. Emphasizing the ecology in parasite community ecology. Trends in Ecology \& Evolution 22: 133-139.
Pimm, S., and J. Lawton. 1980. Are food webs divided into compartments? Journal of Animal Ecology 49: 879-898.

Polis, G. 1991. Complex trophic interactions in deserts: An empirical critique of food-web theory. American Naturalist 138: $123-155$

Poulin, R. 2003. Information about transmission opportunities triggers a life-history switch in a parasite. Evolution 57: 2899-2903. 2007. Are there general laws in parasite ecology? Parasitology 134: 763-776. 1997. Species richness of parasite assemblages: Evolution and patterns. Annual Review of Ecology and Systematics 28: $341-358$.

, and S. Morand. 2000. The diversity of parasites. Quarterly Review of Biology 75: 277-293.

Preston, D. L., A. Z. Jacobs, S. A. Orlofske, and P. T. J. Johnson. 2013. Complex life cycles in a pond food web: Effects of life stage structure and parasites on network properties, trophic positions and the fit of a probabilistic niche model. Oecologia 174: 953-968.

S. A. Orlofske, J. P. McLaughlin, and P. T. J. Johnson. 2012. Food web including infectious agents for a California freshwater pond: Ecological Archives E093-153. Ecology 93: 1760-1760.

Price, P. W. 1980. Evolutionary biology of parasites. Princeton University Press, Princeton, N.J., 256 p.

1987. Evolution in parasite communities. International Journal for Parasitology 17: 209-214.

Read, C. P. 1951. The "crowding effect" in tapeworm infections. Journal of Parasitology 37: 174-178.

1959. The role of carbohydrates in the biology of cestodes. VIII. Some conclusions and hypotheses. Experimental Parasitology 8: 365-382.

and A. Z. Kilejian. 1969. Circadian migratory behavior of a cestode symbiote in the rat host. Journal of Parasitology 55: 574-578.

and K. Phifer. 1959. The role of carbohydrates in the biology of cestodes VII. Interactions between individual tapeworms of the same and different species. Experimental Parasitology 8: 46-50.

Reiczigel, J., Z. Lang, L. Rózsa, and B. Tóthmérész. 2005. Properties of crowding indices and statistical tools to analyze parasite crowding data. Journal of Parasitology 91: 245-252.

Rhodes, C. J., R. Atkinson, R. M. Anderson, and D. W. Macdonald. 1998. Rabies in Zimbabwe: Reservoir dogs and the implications for disease control. Philosophical transactions of the Royal Society of London Series B 353: 999-1010.

Ricklefs, R. E. and Schluter, D. 1993. Species diversity in ecological communities: historical and geographical perspectives. University of Chicago Press, Chicago, I.L., 414 p.

Rohde, K. 1993a. Niche restriction in parasites: Proximate and ultimate causes. Parasitology 109: S69-84.

1991. Intra-and interspecific interactions in low density populations in resource-rich habitats. Oikos 60: 91-104. 
1993b. Ecology of marine parasites: An introduction to marine parasitology. CAB International, Wallingford, U.K., $298 \mathrm{p}$.

Rossiter, W. D. 2012. Impacts of space, abundance and food web structure on parasite life cycles. Ph.D. Thesis, Rutgers University, New Brunswick, New Jersey, 190 p.

Rudolf, V. H., and J. Antonovics. 2005. Species coexistence and pathogens with frequency-dependent transmission. American Naturalist 166: 112-118.

Sanmartín, M. L., M. F. Alvarez, D. Peris, R. Iglesias, and J. Leiro. 2000. Parasite community study of the undulate ray Raja undulata in the Ría of Muros Galicia, northwest Spain. Aquaculture 184: 189-201.

Schad, G. A. 1963. Niche diversification in a parasitic species flock. Nature 198: 404-406.

Schmidt, K., and R. Ostfeld. 2001. Biodiversity and the dilution effect in disease ecology. Ecology 82: 609-619.

Shaw, D. J., and A. P. Dobson. 1995. Patterns of macroparasite abundance and aggregation in wildlife populations: A quantitative review. Parasitology 111: S111-S133.

Shorb, D. A. 1933. Host-parasite relations of Hymenolepis fraterna in the rat and the mouse. American Journal of Epidemiology 18: $74-113$.

Smith, N. 2001. Spatial heterogeneity in recruitment of larval trematodes to snail intermediate hosts. Oecologia 127: $115-122$.

Sousa, W. P. 1992. Interspecific interactions among larval trematode parasites of freshwater and marine snails. Integrative and Comparative Biology 32: 583-592.

Sousa, W. P. 1993. Interspecific antagonism and species coexistence in a diverse guild of larval trematode parasites. Ecological Monographs 63: 104-128.

Sousa, W. P. 1994. Patterns and processes in communities of helminth parasites. Trends in Ecology \& Evolution 9: 52-57.

Stoll, N. R. 1936. Observations on cattle nematode infections, with a demonstration of their secondary transmission to grazing sheep. Journal of Parasitology 22: 386-407.

Sukhdeo, M. V. K. 1992. The behavior of parasitic flatworms in vivo: What is the role of the brain? Journal of Parasitology $\mathbf{7 8}$ : $231-242$.

1990. Habitat selection by helminths: A hypothesis. Parasitology Today 6: 234-237.

1991. The relationship between intestinal location and fecundity in adult Trichinella spiralis. International Journal for Parasitology 21: 855-858.

1997. Earth's third environment: The worm's eye view. Bioscience 47: 141-149.

2000. Inside the vertebrate host: Ecological strategies by parasites living in the third environment. In Evolutionary biology of host-parasite relationships: Theory meets reality, R. Poulin, S. Morand, and A. Skorping (eds.). Elsevier Science, New York, p. 43-62.

and Mettrick, D. F. 1987. Parasite behaviour: Understanding platyhelminth responses. Advances in Parasitology 26: $73-144$. and Hernandez, A. D. 2005. Food web patterns and the parasite's perspective. In Parasitism and ecosystems, F. Thomas, F. Renaud, and J. -F. Guegan (eds.). Oxford University Press, Oxford, U.K., p. 54-67.

and Sukhdeo, S. C. 2004. Trematode behaviours and the perceptual worlds of parasites. Canadian Journal of Zoology 82: 292-315.

. 2010. Food webs for parasitologists: A review. Journal of Parasitology 96: 273-284.

2012. Where are the parasites in food webs? Parasites and Vectors 5: 239.

Sukhdeo, S. C., M. V. K. Sukhdeo, and D. F. Mettrick. 1988. Histochemical localization of acetylcholinesterase in the cerebral ganglia of Fasciola hepatica, a parasitic flatworm. Journal of Parasitology 74: 1023-1032. , and

1988b. Neurocytology of the cerebral ganglion of Fasciola hepatica (Platyhelminthes). Journal of Comparative Neurology 278: 337-343.

Thieltges, D. W., K. Reise, K. N. Mouritsen, J. P. McLaughlin, and R. Poulin. 2011. Food web including metazoan parasites for a tidal basin in Germany and Denmark: Ecological Archives E092-E172. Ecology 92: 2005-2005.

Thomas, F., F. Renaud, T. de Meeūs, and R. Poulin. 1998. Manipulation of host behaviour by parasites: Ecosystem engineering in the intertidal zone? Proceedings of the Royal Society of London: Series B 265: 1091-1096.

Thompson, R. M., R. Poulin, K. N. Mouritsen, and D. W. Thieltges. 2013. Resource tracking in marine parasites: Going with the flow? Oikos 122: 1187-1194.

K. Mouritsen, and R. Poulin. 2005. Importance of parasites and their life cycle characteristics in determining the structure of a large marine food web. Journal of Animal Ecology 74: 77-85.

Thrall, P. H., J. Antonovics, and D. W. Hall. 1993. Host and pathogen coexistence in sexually transmitted and vector-borne diseases characterized by frequency-dependent disease transmission. American Naturalist 142: 543-552.

Valtonen, E. T., K. Pulkkinen, R. Poulin, and M. Julkunen. 2001. The structure of parasite component communities in brackish water fishes of the northeastern Baltic Sea. Parasitology $\mathbf{1 2 2}$ : 471-481.

Volterra, V. 1926. Fluctuations in the abundance of a species considered mathematically. Nature 118: 558-560.

Ward, H. B. 1912. The distribution and frequence of animal parasites and parasitic diseases in North American fresh-water fish. Transactions of the American Fisheries Society 41: 207-244.

Warren, P. H. 1989. Spatial and temporal variation in the structure of a freshwater food web. Oikos 55: 299-311.

Weinersmith, K. L., C. B. Warinner, V. Tan, D. J. Harris, A. B. Mora, A. M. Kuris, K. D. Lafferty, and R. F. Hechinger. 2014. A lack of crowding? Body size does not decrease with density for two behavior-manipulating parasites. Integrative and Comparative Biology 54: 184-192. 
Williams, R. J., and N. D. Martinez. 2004. Limits to trophic levels and omnivory in complex food webs: Theory and data. American Naturalist 163: 458-468.

Wilson, C. B. 1916. Copepod parasites of fresh-water fishes and their economic relations to mussel glochidia. Bulletin of the Bureau of Fisheries 824: 331-374.

Woodland, W. N. F. 1924. On a new Bothriocephalus and a new Genus of Proteocephalidae from Indian fresh-water fishes. Parasitology 16: 441-451.
Woolhouse, M., L. Taylor, and D. Haydon. 2001. Population biology of multihost pathogens. Science 292: 1109-1112.

Zervos, S. 1988a. Evidence for population self-regulation, reproductive competition and arrhenotoky in a thelastomatid nematode of cockroaches. Parasitology 96: 369-379.

Zervos, S. 1988b. Population dynamics of a thelastomatid nematode of cockroaches. Parasitology 96: 353-368. 


\section{A PROBABLE CASE OF NON-SPECIFIC IMMUNITY BETWEEN TWO PARASITES OF CISCOES OF THE TROUT LAKE REGION OF NORTHERN WISCONSIN}

It has been noted by several investigators that the presence of large numbers of one species of parasites has a tendency to limit infection by other parasites. Ward (Trans. Amer. Fish. Soc., I9II, 207) states: "Few fishes shelter equal numbers of all kinds of parasites and no species is recorded as heavily infected with all four groups of intestinal worms." Wilson (Bull. Bur. Fish., 34:333, I9I4) in a study of the glochidia of fresh-water mussels, showed that fish heavily infected with copepods were either very lightly or not at all infected with glochidia. He found also from the examination of field specimens that those fish harboring a large number of glochidia had few or no copepods. Leigh-Sharpe (Parasit., 25, I933) says: "Monogenetic trematodes were found in greater abundance on the gills of fishes than parasitic copepoda and seemed mutually exclusive." Nolf and Cort (Jour. Parasit., 20:38, 1933) found, in the case of groups of snails infested with larval stages of a schistosome, evidence of a non-specific immunity to infection by metacercariae of a strigeid trematode, Cotylurus flabelliformis.

As part of the fish parasite investigation fostered by the Wisconsin Geological and Natural History Survey, a catch of 92 ciscoes from Silver Lake were examined in 1933. In this group no parasites were found other than adult cestodes of the species Proteocephalus exigus and Acanthocephala of the genus Neoicanthorinchus. In the series of 92 fish the average number of tapeworms harbored was 16.92 and the average number of acanthocephala was 8.3. Of these fish 84 harbored tapeworms, 73 harbored acanthocephala and every fish had one or both parasites.

The degree of infection of this group of fish is plotted in Figure I. From this graph it will be seen that those fish having 15 or more acanthocephala had a very limited infection with tapeworms. Conversely those harboring more than 25 tapeworms had few or no acanthocephala. The fish with fewer parasites often have them quite evenly divided between the two types.

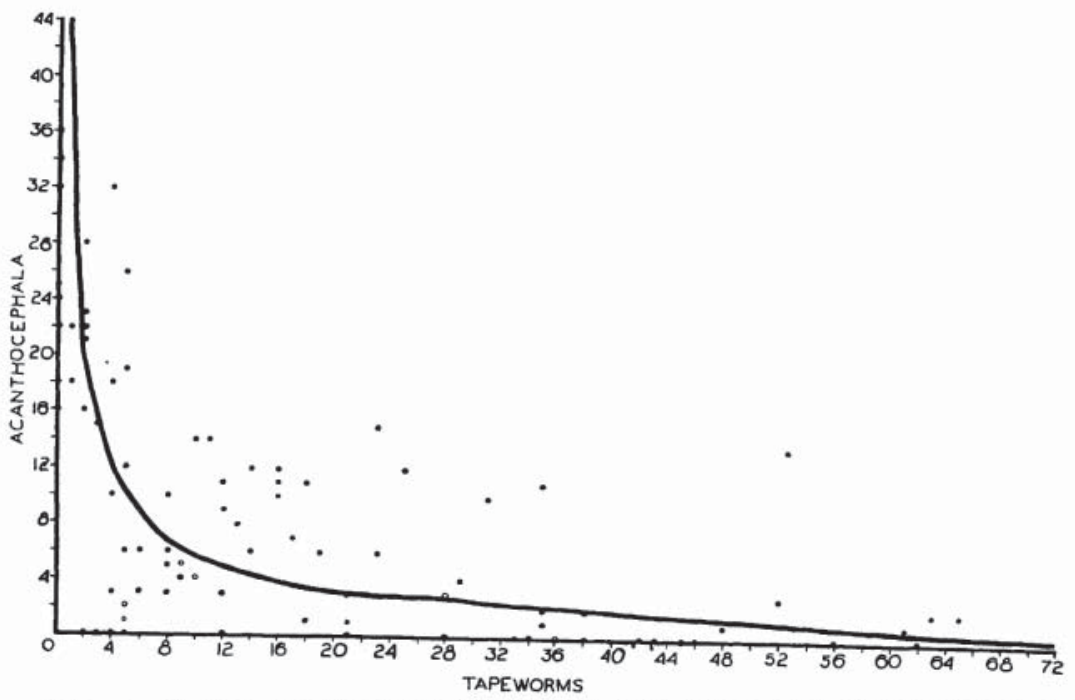

Fig. I. Degree of infection of individual fish. The curve on this graph was located from a free hand line drawn on a logarithmic graph.

One dot represents I fish.

One circle represents 2 fish with similar infections. 
In Table I the first group is made up of all fish harboring 28 or more tapeworms. Remembering the average tapeworm and acanthocephala infections it is evident that the tapeworm infection in this group is far higher than average

TABLE I.-Averages of infections in arbitrary groups from Figure $I$

\begin{tabular}{|c|c|c|c|}
\hline Limits of infection & $\begin{array}{l}\text { Number } \\
\text { of fish }\end{array}$ & $\begin{array}{l}\text { Average tape- } \\
\text { worm infection }\end{array}$ & $\begin{array}{c}\text { Average } \\
\text { acanthocephala } \\
\text { infection }\end{array}$ \\
\hline 1. 28 tapeworms or more ...... & 23 & 42.09 & 1.9 \\
\hline 2. 20 acanthocephala or more .... & 12 & 1.33 & 27 \\
\hline 3. 15-25 tapeworms $\ldots \ldots \ldots \ldots$ & 13 & 19.53 & 7.3 \\
\hline 4. $10-20$ acanthocephala $\ldots \ldots \ldots$ & 22 & 11.7 & 13.59 \\
\hline 5. 1-15 tapeworms $\ldots \ldots \ldots \ldots$ & 45 & 6.62 & 9.62 \\
\hline 6. 1-10 acanthocephala $\ldots \ldots \ldots$ & 45 & 19.87 & 4.21 \\
\hline
\end{tabular}

while the acanthocephala infection is only a fraction of the average for these worms. In the second item in Table $I$ the high acanthocephala infections are averaged using those cases with 20 or more of these worms. Here the infection with acanthocephala is far above the average with tapeworms very low.

That this phenomenon is not due to crowding of the parasites in the intestine is evident when we consider that the two species occupy different parts of the alimentary tract, the tapeworms preferring the gastric caeca as points of attachment while the acanthocephala attach themselves near the middle of the intestine. With this in mind it seems reasonable to think of this situation as a result of a non-specific immunity limiting either tapeworms or acanthocephala when one of these parasites is present in large numbers.-SAM UEL X. CROSS, Limnological Laboratory, Wisconsin Geological and Natural History Survey. (Note No. 53.) 